\section{DNDi, MPP speed up in hepatitis C pan-genotypic treatment access}

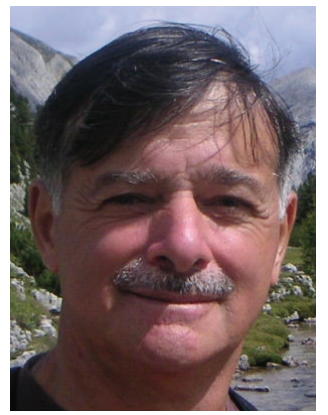

\author{
“Affordable hepatitis C virus pan-genotypic \\ direct-acting antiviral regimens would get rid of \\ the costs for genotype testing and allow an \\ increasing number of patients in low- and middle- \\ income countries to be treated."
}

Daniele Dionisio*

First draft submitted: 25 November 2016; Accepted for publication: 2 December 2016; Published online: 20 January 2017

A major cause of liver cancer and cirrhosis, chronic infection by hepatitis $\mathrm{C}$ virus (HCV) affects more than 80 million people worldwide, $85 \%$ of whom live in low $(13 \%)$ and middle (72\%) income countries (LMICs) [1]. Around 15\% of Egypt's population, for example, is infected - one of the world's highest prevalence rate - while it is estimated that 12 million people in India have hepatitis $\mathrm{C}$ [2].

At least 1.2 million people in Japan and three million Americans suffer from hepatitis C, while in Europe the infection ranks high as a public-health challenge (between 0.4 and $3.5 \%$ of the population in different EU Member States) and the most common single cause of liver transplantation [3-5].

Nearly 700,000 people are killed by hepatitis $\mathrm{C}$ yearly [1].

The field of HCV therapeutics came to a turning point in 2013 with the rollout of a new class of medicines called directacting antivirals (DAAs). By blocking vital steps for HCV to replicate, they have shown high efficacy, mainly when used in combination (cure rates in excess of $90 \%$ after 12 -week treatment), with a reliable safety profile [6].

Access to these regimens is, however, a difficult task since these drugs were marketed at stiff prices making the scale-up of treatments an unbearable burden for healthcare systems all over the world.

Fortunately, WHO data show that over one million people in LMICs have benefited from DAAs to date [1]. These results were mostly achieved by affordable generic equivalents competition on the market through voluntary license (VL) and patentsharing programs as part of the strategies available to overcome intellectual property and pricing barriers (Box 1).

Regrettably, while the annual amount of new HCV infections exceeds the number of patients entering treatment, DAA prices remain out of reach in some middle-income countries excluded from generic formulations and VL agreements. Just for example, the price for a 3-month treatment of DAAs sofosbuvir and daclatasvir ranges from US\$9400 in Brazil to US\$79,900 in Romania [1].

This is without prejudice to the awareness that $\mathrm{R} \& \mathrm{D}$ for the DAAs has been centered on HCV genotypes predominant in the most affluent countries, with little data available on efficacy in heavily burdened LMICs where genotype 3 accounts for $30 \%$

*European Parliament Working Group on Innovation, Access to Medicines and Poverty-Related Diseases; Policies for Equitable Access to Health (PEAH); d.dionisio@tiscali.it

\section{KEYWORDS}

- affordable treatment $\bullet$ directacting antivirals $\bullet$ hepatitis $\mathrm{C} \bullet$ lowand middle-income countries 


\author{
"Regrettably, while the \\ annual amount of new \\ hepatitis $C$ virus infections \\ exceeds the number of \\ patients entering \\ treatment, direct-acting \\ anitviral prices remain out \\ of reach in some middle- \\ income countries excluded \\ from generic formulations \\ and voluntary licence \\ agreements."
}

of global HCV infection.

Against the backdrop outlined above, the initiatives taken by Drugs for Neglected Diseases (DNDi) and Medicines Patent Pool (MPP) organizations are worth mentioning (Box 2) [8,9]. Their efforts are complementary to and synergistic with WHO's staunch engagement in the field as embodied in the recent 'Global Report on Access to Hepatitis C Treatment: Focus on Overcoming Barriers' [10].

\section{DNDi strategy}

In April 2016, in partnership with the governments of Malaysia and Thailand, DNDi and the Egyptian generic drug manufacturer Pharco Pharmaceuticals signed an agreement to undertake a 2-year (2016-2017) Phase III clinical study to evaluate sofosbuvir (approved in the USA and Europe for HCV genotypes 1-6) plus the DAA drug candidate ravidasvir (developed by biotech Presidio Pharmaceuticals) as an useful pan-genotypic regimen [7,11].

The agreement followed in the wake of a high response rate in genotype $4 \mathrm{HCV}$ patients treated with ravidasvir and sofosbuvir combination in Egypt [12].

Currently, DNDi and the Presidio licensee Pharco are testing the efficacy, safety and pharmacokinetics of the combination in nearly 1000 patients with different genotypes and liver fibrosis level, with or without HIV co-infection. Based on the study success, the combination will be supplied at less than $\$ 300$ price tag per treatment course, with further price cuts following higher sales volumes and increased competition.

Malaysia and Thailand were chosen because of high HCV prevalence ( 0.4 and 0.9 million, respectively), in particular genotype 3 , and their exclusion from VL agreements for recently approved DAAs [7].

Affordable pan-genotypic DAA regimens would get rid of the costs for genotype testing and allow an increasing number of patients with hepatitis C in LMICs to be treated.

As reported "...Presidio has granted DNDi a non-exclusive license to ravidasvir for LMICs. In addition, it has given DNDi an option to take non-exclusive licenses to high-income countries after a two-year period. The licenses include a full complement of rights to enable DNDi to develop ravidasvir as a treatment for HCV and to register, manufacture, distribute and sell the treatment in the countries covered, either by itself or with a partner.

In return for the licensing rights, Presidio will receive single-digit royalties on net commercial sales of the treatments. The treatments will be sold on an affordable basis, delinking R\&D costs from the price of the product, meaning that the price will be based on manufacturing and distribution costs, not R\&D costs, plus a small but sustainable margin.

Presidio will make further efforts to promote affordable access to ravidasvir by considering offers from other interested organizations to take non-exclusive licenses, and including in any license agreement the same affordable access terms as agreed with DNDi, meaning the single-digit royalties on net sales and affordable pricing." [7].

\section{MPP engagement}

In November 2015, at a time when the MPP broadened its mandate to cover hepatitis $\mathrm{C}$, Bristol-Myers Squibb entered with it into a royaltyfree VL agreement for daclatasvir, an already

\section{Box 1. Ways to affordable hepatitis $C$ virus treatment.}

- Negotiation - with pharmaceutical companies to secure equitable access to new HCV treatments at a price that is genuinely affordable to patients and health systems, based on local economic conditions.

- Licensing of key HCV medicines - including under voluntary license programs that open all LMICs to generic competition, and patent sharing through organizations such as the MPP. Patent sharing is an effective way of sharing innovative products in resource-poor settings. Low-cost producers and product-development partnerships can make and sell affordable, adapted HCV medicines, and sales may be compensated by a fair royalty.

- Tiered pricing - in which the drug price is set by the manufacturers according to local economic conditions to ensure equitable access and affordability.

- Patent opposition - also called patent challenge, a procedure administered by the patent office of a country which allows any third party to oppose the granting of a patent on grounds that it does not meet the standards for patentability under that country's laws, for example, lack of novelty.

- Compulsory licensing - by which LMICs exercise their rights to allow generic producers to manufacture selected drugs that are under patent protection, and compensate the patent holders based on a set of predetermined criteria.

HCV: Hepatitis C virus; LMIC: Low- and middle-income countries; MPP: Medicines patent pool.

Reproduced from DNDi [7]. 


\section{Box 2. DNDi and MPP profiles.}

- DNDi - is a collaborative, patients' needs-driven, non-profit drug R\&D organization that is developing new treatments for neglected diseases. DNDi's hepatitis C drug development strategy aims to meet the specific needs of HCV patients in LMICs by developing a short-course, affordable, highly efficacious, safe and all-oral pan-genotypic regimen that will enable countries to implement a 'public health approach' whereby all those infected, not only those in immediate need of therapy, will be treated [8].

- MPP - is a United Nations-backed public health organization working to increase access to HIV, viral hepatitis C and tuberculosis treatments in LMICs. The MPP partners with governments, industry, civil society, international organizations, patient groups and other stakeholders to forecast, prioritize and license needed medicines. As for hepatitis $C$, the organization works with brand and generic drug companies and seeks to license new and pipeline pan-genotypic DAAs for generic manufacture [9].

DAA: Direct-acting antiviral; DNDi: Drugs for neglected diseases initiative; HCV: Hepatitis C virus; LMIC: Low- and middle-income countries; MPP: Medicines patent pool.

approved DAA by the EMA for HCV genotypes 1-4 [13]. The key features of the license are summed up as follows [14]:

- The license allows for the manufacturing of generic active pharmaceutical ingredient and finished formulations of daclatasvir anywhere in the world. It enables generic manufacture of daclatasvir for sale at least in 112 LMICs that are home to $65.4 \%$ of people living with $\mathrm{HCV}$;

- A technology transfer package is provided to all the licensees, but there is no obligation to use the technology. Licensees are authorized to sell outside the licensed territory, so as long as they do not use the technology transferred from the originator company, and do not infringe patents;

- Licensees must obtain approval from the WHO Prequalification Programme, or a stringent drug regulatory authority. Where such approval is not yet available, temporary approval from a WHO Expert Review Panel may be obtained;

- Data exclusivity is waived, and sub-licenses can be issued to qualified entities worldwide;

- Licensees and sub-licensees have the right to combine daclatasvir with other DAAs not owned by Bristol-Myers Squibb and to develop new fixed-dose combinations.
So far, seven Indian companies - Aurobindo, Cipla, Emcure, Hetero, Laurus, Natco and Zydus Cadila - have signed the licensing agreement with the MPP. These circumstances entail sharp reductions in prices owing to strong market competition.

While the MPP license covers more than twothirds of all middle-income countries, it does exclude several countries with high HCV burden, including Brazil, China, Mexico, Ukraine, Thailand and Malaysia. Relevantly, it is worth mentioning that, as part of DNDi underway project, Presidio Pharmaceuticals will consider entering into negotiations with the MPP for the granting of additional non-exclusive licenses in order to speed up and broaden the manufacture and distribution of ravidasvir [7].

\section{Financial \& competing interests disclosure}

Daniele Dionisio is a member of the European Parliament Working Group on Innovation, Access to Medicines and Poverty-Related Diseases, and head of the research project PEAH - Policies for Equitable Access to Health. Dionisio is former director of the Infectious Disease Division at the Pistoia City Hospital (Italy). He may be reached at d.dionisio@tiscali.it; http://www.peah.it/; https://twitter. com/DanieleDionisio. The author has no other relevant affiliations or financial involvement with any organization or entity with a financial interest in or financial conflict with the subject matter or materials discussed in the manuscript apart from those disclosed.

No writing assistance was utilized in the production of this manuscript.

\section{References}

1 Over 1 million treated with highly effective hepatitis $\mathrm{C}$ medicines. WHO. www.who.int/

2 Natco tries to block hepatitis $\mathrm{C}$ patent in India. GaBI. www.gabionline.net/

3 Japan approves first all-oral, interferon- and ribavirin-free hepatitis $\mathrm{C}$ treatment,
Daklinza $^{\circledR}$ (daclatasvir) and Sunvepra ${ }^{\circledR}$ (asunaprevir) dual regimen. BMS http://news.bms.com/

4 Merck bids $\$ 3.8$ billion for an edge in hepatitis. The New York Times. http://dealbook.nytimes.com/

5 European Medicines Agency recommends approval of Daklinza in chronic hepatitis C. www.ema.europa.eu/
6 Major breakthrough in Hepatitis $\mathrm{C}$ therapy: Daclatasvir and Sofosbuvir combination attains functional cure in more than $90 \%$ of patients with Hepatitis C. Specialty pharmacy times. www.specialtypharmacytimes.com/

7 DNDi: an alternative research and development strategy to deliver affordable treatments for Hepatitis $\mathrm{C}$ patients. www.dndi.org/wp-content/ 


\section{EDITORIAL Dionisio}

8 Drugs for neglected diseases initiative. DNDi.

www.dndi.org/about-dndi/

9 The Medicines Patent Pool. MPP. www.medicinespatentpool.org/about/

10 WHO's global report on access to hepatitis C treatment: focus on overcoming barriers. http://apps.who.int/iris/
11 Sofosbuvir approved in the US and Europe for HCV genotypes 1-6. HIV Treatment Bulletin.

http://i-base.info/htb/24578

12 Boston CROI Conference, February 2016: high response rate in HCV-genotype 4 patients treated with Ravidasvir and Sofosbuvir.

www.croiconference.org/sessions/
13 Daclatasvir approved in EU for HCV genotypes 1-4. HIV treatment bulletin. http://i-base.info/htb/27430

14 MPP licence for Daclatasvir.DCV. www.medicinespatentpool.org/ 